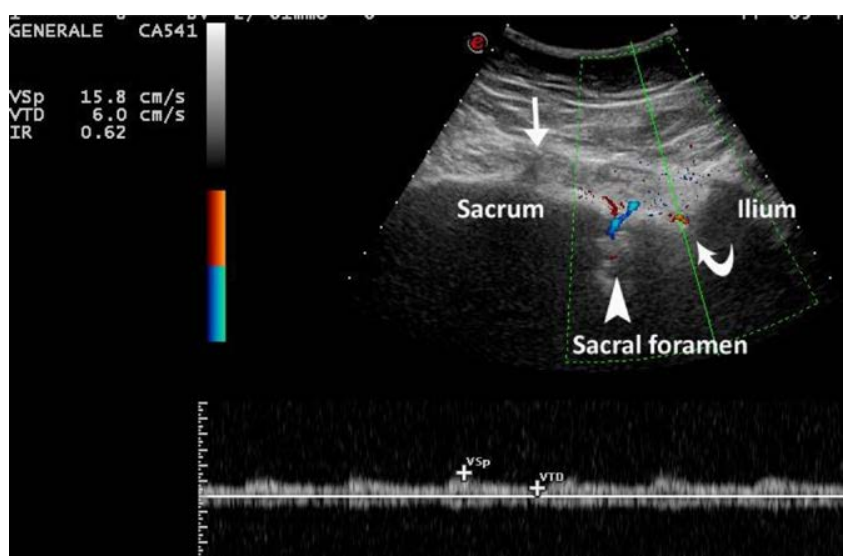

Disclosure of Interests: None declared.

DOI: 10.1136/annrheumdis-2021-eular.998

\section{POS0964 CHARACTERISTICS AND BURDEN OF DISEASE IN PATIENTS WITH RADIOGRAPHIC VERSUS NON- RADIOGRAPHIC AXIAL SPONDYLOARTHRITIS IN THE ANKYLOSING SPONDYLITIS REGISTRY OF IRELAND COHORT}

S. Quinn ${ }^{1}$, S. Maguire ${ }^{2}$, F. B. O'shea ${ }^{2}$, L. O'neill', E. Molloy' ${ }^{1}$ U. Fearon ${ }^{3}$, P. Gallagher', D. Veale ${ }^{1}{ }^{1}$ St. Vincent's University Hospital, Rheumatology, Dublin, Ireland; ${ }^{2}$ St James's Hospital, Rheumatology, Dublin, Ireland; ${ }^{3}$ Trinity Biomedical Sciences Institute, Molecular Rheumatology, Dublin, Ireland

Background: Axial spondyloarthritis (axSpA) is an umbrella term for types of inflammatory arthritis that primarily affect the spine and the sacroiliac joints. It is comprised of patients with both radiographic $(\mathrm{r}-\mathrm{axSpA})$ and non-radiographic features (nr-axSpA). R-axSpA was historically known as Ankylosing Spondylitis. Previous studies have shown the burden of disease to be largely similar in patients with radiographic versus non-radiographic axial spondyloarthritis in cohorts both in the US and Europe [1]. The Ankylosing Spondylitis Registry of Ireland (ASRI) was formed with the objective to measure the burden of axial spondyloarthritis in the population and identify early predictors of a poor outcome. All patients in the registry are 18 years or older and meet Assessment of Spondyloarthritis International Society (ASAS) criteria for a diagnosis of SpA. Objectives: To compare the characteristics and burden of disease in patients with radiographic versus non-radiographic axial spondyloarthritis in the ASRI cohort.

Methods: Patients with radiographic axial spondyloarthritis (r-axSpA) were defined as those with $x$-ray evidence of sacroilitis. Patients with non-radiographic axial spondyloarthritis (nr-axSpA) were defined as having MRI evidence of sacroilitis but no $x$-ray evidence of sacroilititis. A standardised clinical assessment was performed on each patient and structured interviews provided patient-reported data. For each patient the following scores were captured: Bath Ankylosing Spondylitis Disease Activity Index (BASDAI), Bath Ankylosing Spondylitis Functional Index (BASFI), Bath Ankylosing Spondylitis Metrology Index (BASMI), Health Assessment Questionnaire ( $\mathrm{HAQ}$ ) assesses the self-reported functional status for performing activities of daily living, and the Ankylosing Spondylitis Quality of Life (ASQoL) questionnaire. Categorical variables were summarized as percentages with frequency counts, and continuous variables with a mean and standard deviation. Statistical comparisons between subgroups were evaluated using 2 sample t-tests for continuous variables and chi-square tests for categorical variables.

Results: 764 patients were available for analysis. Analysis of radiographic status showed $88.1 \%(n=673)$ of patients with $r-a x S p A$ and $11.9 \%(n=91)$ with $n r-a x S p A$. Patients with nr-axSpA were younger (41.3 vs. 46.6 years, $p<0.01)$, had shorter disease duration (14.8 vs. 20.2 years, $p<0.01$ ), lower proportion of males $(66.6 \%$ vs. $78.4 \%, p=0.02)$ with lower rates of HLA-B27 positivity $(73.6 \%$ vs. $90.5 \%$, $p<0.01$ ). The nr-axSpA group had lower BASDAI (3.37 vs. $4.05, p=0.01$ ), BASFI (2.46 vs. $3.88, p<0.01$ ), BASMI ( 2.33 vs. $4.34, p<0.01$ ), ASQoL (5.2 vs. 6.67 , $\mathrm{p}=0.02$ ), and $\mathrm{HAQ}$ scores $(0.38$ vs. $0.57, \mathrm{p}<0.01$ ). There were no significant differences in the prevalence of extra-articular manifestations.

Conclusion: This study provides evidence that the burden of disease is less in patients with non-radiographic axial spondyloarthritis than radiographic axial spondyloarthritis, as demonstrated by better BASDAI, BASFI, BASMI, HAQ and ASQoL scores.

REFERENCES:

[1] López-Medina C, et al. Characteristics and burden of disease in patients with radiographic and non-radiographic axial Spondyloarthritis: a comparison by systematic literature review and meta-analysis. RMD Open, 2019. 5(2) p1108.
Table 1.

\begin{tabular}{lccc}
\hline & r-axSpA & nr-axSpA & $p$ value \\
\hline $\mathbf{n}$ & 673 & 91 & \\
Age (years) & $46.6(+/-12.4)$ & $41.3(+/-12.4)$ & $<0.01$ \\
Disease duration (years) & $20.2(+/-12.4)$ & $14.8(+/-11.7)$ & $<0.01$ \\
Delay to diagnosis (years) & $8.41(+/-8.6)$ & $6.34(+/-7.2)$ & 0.03 \\
Males & $78.8 \%(528)$ & $65.9 \%(60)$ & 0.02 \\
Females & $21.5 \%(145)$ & $34.1 \%(31)$ & 0.02 \\
HLA-B27+ & $90.50 \%(440$ of 486 & $73.60 \%(53$ of 72 & $<0.01$ \\
& available results) & available results) & \\
BASDAI & $4.05(+/-2.39)$ & $3.37(+/-2.31)$ & 0.01 \\
BASFI & $3.88(+/-3.00)$ & $2.46(+/-2.39)$ & $<0.01$ \\
BASMI & $4.34(+/-2.08)$ & $2.33(+/-1.42)$ & $<0.01$ \\
ASQoL & $6.67(+/-5.55)$ & $5.2(+/-5.53)$ & 0.02 \\
HAQ & $0.57(+/-0.54)$ & $0.38(+/-0.44)$ & $<0.01$ \\
Psoriasis & $17.8 \%(120)$ & $15.4 \%(14)$ & 0.31 \\
IBD & $11 \%(74)$ & $8.8 \%(8)$ & 0.58 \\
Uveitis & $33.9 \%(228)$ & $34.1 \%(31)$ & 0.54 \\
\hline
\end{tabular}

Disclosure of Interests: Sean Quinn: None declared, Sinead Maguire: None declared, Finbar Barry O'Shea: None declared, Lorraine O'Neill: None declared, Eamonn Molloy: None declared, Ursula Fearon Speakers bureau: Abbvie, Grant/ research support from: Janssen, Abbvie, Pfizer, UCB, Phil Gallagher: None declared, Douglas Veale Speakers bureau: AbbVie, BMS, Celgene, Pfizer, MSD, Roche, Consultant of: AbbVie, Actelion, BMS, Novartis, Pfizer, MSD, Roche, Regeneron/Sanofi, Grant/research support from: AbbVie, Pfizer, MSD, Novartis, Roche, Janssen.

DOI: 10.1136/annrheumdis-2021-eular.1056

\section{POS0965 ARE SMOKING AND ALCOHOL ASSOCIATED WITH PERIPHERAL MUSCULOSKELETAL INVOLVEMENT IN PATIENTS WITH SPONDYLOARTHRITIS? RESULTS FROM THE ASAS-PERSPA STUDY}

M. L. Ladehesa Pineda ${ }^{1}$, R. Ortega Castro ${ }^{1}$, M. Á. Puche Larrubia ${ }^{1}$, M. Dougados ${ }^{2}$, E. Collantes Estevez ${ }^{1}$, C. López-Medina ${ }^{1,2} .{ }^{1}$ Córdoba, Rheumatology Department, Reina Sofia University Hospital, IMIBIC, University of Córdoba, Córdoba, Spain, Córdoba, Spain; ${ }^{2}$ Paris, Rheumatology Department, Cochin Hospital, Paris, France, Paris, France

Background: The harmful effect of smoking on axial spondyloarthritis (axSpA) in relation to radiographic progression is well known, but there are controversies around the role of cigarettes in other manifestations of $\mathrm{SpA}$, such as peripheral involvement. Besides, it has been observed an inverse association between alcohol consumption and disease activity and functional impairment ${ }^{1}$, although it is still unclear its association with peripheral manifestations of $\mathrm{SpA}$.

Objectives: To evaluate the association between smoking/alcohol intake and the prevalence of peripheral articular manifestations (arthritis, enthesitis or dactylitis).

To assess the association between smoking/alcohol intake and the location of such manifestations.

Methods: Patients from the cross-sectional ASAS-PerSpA study with available data for both the smoking status and alcohol intake were included. Mixed logistic regressions using the peripheral manifestation (or location) as dependent variable, the smoking status or alcohol intake as fixed effect and the country as random effect were used. The interaction between smoking and alcohol was tested. Results: A total of 4451 patients with either axSpA, peripheral SpA or Psoriatic Arthritis were included. 59.5\% had smoked at any moment and $42.7 \%$ had been alcohol drinkers. Patients who had ever suffered arthritis showed lower frequency of smoking habit $(\mathrm{OR} 0.72,95 \% \mathrm{Cl} 0.63-0.82)$ and lower alcohol intake (OR $0.82,95 \% \mathrm{Cl} 0.71-0.94$ ) (Table 1). Among patients with arthritis, smoking was associated with predominantly upper limbs vs. lower limbs involvement (OR $0.78,95 \% \mathrm{Cl} 0.65-0.94)$, while alcohol was associated with predominant mono/ oligoarticular vs. polyarticular involvement (OR 1.13, 95\% Cl 0.94-1.36).

Patients who had ever suffered enthesitis also showed lower frequency of smoking habit and alcohol intake (OR 0.75, 95\% $\mathrm{Cl} 0.63-0.89$ and OR $0.69,95 \% \mathrm{Cl} 0.57-0.83$, respectively). No association was found with regard to the prevalence of dactylitis.

At the moment of the study visit, $20.4 \%$ patients were current smokers and $32.2 \%$ consumed alcohol. Current alcohol intake was associated with lower prevalence of current arthritis $(26.9 \%$ vs. $33.6 \%$ (OR $0.76,95 \% \mathrm{Cl} 0.64-0.91)$ and current enthesitis $(21.1 \%$ vs. $34.6 \%$ (OR $0.78,95 \% \mathrm{Cl} 0.62-0.96)$, while current smoking did not show significant differences.

No interaction was found in the association between alcohol and tobacco with regard to the prevalence of peripheral symptoms in the past. However, when assessing current arthritis, current smoking and no drinking was associated with arthritis in the lower limbs.

Conclusion: These results suggest that, taking into account the country, smoking and alcohol are associated with lower prevalence of peripheral manifestations (arthritis 